\title{
Accounting decoupled: a case study of accounting regime change in a Malaysian company
}

\author{
Shi-Min How \\ The University of Nottingham, Malaysia Campus, Malysia. \\ How.ShiMin@nottingham.edu.my
}

\author{
Chandana Alawattage \\ University of Aberdeen Business School, University of Aberdeen, Scotland, UK \\ c.g.alawattage@abdn.ac.uk
}

\begin{abstract}
Using a case study of accounting regime change in a Malaysian company, this paper analyses how an accounting regime was changed to overcome an instance of decoupling that management of the case company perceived to be problematic and, despite certain technological and managerial improvements, why the accounting regime yet remained decoupled from the control of core operations. Through an eclectic use of ANT, neo-institutionalism and political economy, it demonstrates that accounting remains decoupled from operational processes because of the particular manner in which accounting is constructed and enabled; the ostensive characteristics of accounting objects around which performativity of accounting is defined; and the organisational context, which involves certain 'political imperfections' that cannot be narrated within organisational apparatus of modernity. Accounting, being an apparatus of modernity, finds it difficult to codify such 'imperfections' and to offer an operational doctrine to govern the real business processes that are embedded within these 'imperfections. Hence, it remains decoupled from core operational activities but performs an important role of insulating 'political imperfections' with which business operates.
\end{abstract}

Key words: decoupling, accounting regime change, SAP implementations, sociology of translation, accounting in Less Developed Countries. 


\section{Introduction: the problem of decoupled accounting}

How important accounting is in controlling day-to-day business operations has long been debated. The taken for granted orthodoxy has been that accounting plays a vital role in operational controls. Accounting is presumed to be an objective source of information that corporate managers use in a rational and authoritarian way in pursuit of economic ends (cf. Bryer, 2006, Mackintosh, 1994). Bryer (2006) argues that "accounting is the most important control system because it provides the investors and managers with objective measures of the generation and realisation of surplus value; ... accounting is the totality of the control process because it provides an objective framework within which all other control systems and realities are subsidiary and subservient" (p. 552). While Bryer's argument rests on the potential of accounting to translate capitalist ideologies into a set of operational doctrines at the point of production, the managerial functionality and potential of accounting has been much emphasised in relation to the technological potential of computerised accounting packages for unprecedented levels of organisational integration (see Davenport, 1995, 1998, 2000, McAdam and Galloway, 2005). Quite a few critical researchers, on the other hand, have different ideas. For Emmanuel et al. (1990, p.34), for example, accounting is just one technique available to assist organisational control and would be neither the totality of all control systems nor the most important one.

Empirical findings on accounting in Less Developed Countries (LDCs) do not support the attribution of a managerial significance to accounting. Instead, it has been understood that accounting does not constitute a dominant form of control and has become marginal, ritualistic, ceremonial and decoupled from operations. For example, Uddin and Hopper's (2001, p.643) case study of a Bangladeshi soap manufacturing company demonstrates how "accounting ... became marginal, ritualistic, and de-coupled from operations". Alawattage and Wickramasinghe (2008) argue that the role accounting has assumed within political hegemonies of the LDC is not constitutive of the political hegemony of controlling labour. Hoque and Hopper's (1994) paper on a Bangladeshi jute mill also conveys the message that accounting is not the dominant form of control in LDCs. Jack and Kholeif (2008) and Kholeif et al. (2007) also observed a similar pattern in case studies of enterprise resource-planning (ERP) implementation in Egypt. They demonstrate how ERP implementations failed to achieve their intended integration and control functions (Jack and Kholeif, 2008 , p.43). All these studies, one way or the other, demonstrate that accounting has been decoupled from the operational core of the business.

The notion of decoupled accounting is not necessarily an LDC phenomenon and, hence, more than any of those LDC studies, it is Berry et al.s (1985) classic case of the British National Coal Board (NCB) that provides a clearer point of reference for this paper. Berry et al. (1985) observes how NCB manages its business through a vertically and horizontally decoupled management control system where each part of the organisation maintains its own identity and separateness. Intra-organisational relationships between its parts were observed to 
be relatively infrequent, weak in terms of mutual effects and slow in mutual response (Berry et. al. 1985, p.14). Nonetheless, in contrary to the negativity attributed to decoupling in the above mentioned LDC research, they argue, such a decoupling in control systems would not necessarily be undesirable but it has enabled the NCB to manage varying types and degrees of complexity and uncertainty. Covaleski and Dirsmith's (1983) also make a very similar observation of how budgeting operate as a means of loose/decoupling between external imagery and internal operations and, for them, such a decoupling is forced through budgeting, because decoupling will not arise spontaneously. The notion of decoupling is, perhaps, best spelled out by Meyer and Rowan's classic (1977) - Formal Structure as Myth and Ceremony, where they argue that, "to maintain ceremonial conformity, organisations that reflect institutional rules tend to buffer their formal structures from the uncertainties of technical activities by becoming loosely coupled, building gaps between their formal structures and actual work activities" (p.341). Such a decoupling is necessary, inter alia, for (1) the insulation of the presumed functionalities of the imagery structure from the anomalies of the organisations operational/technical core and (2) the conformance to the formal structure while still preserving the autonomy and the ability of the operational/technical structure to be responsive to a loosely coupled world (Meyer and Rowan, 1977; see also, Covaleski and Dirsmith, 1983; Weick, 1976).

Accounting research on LDCs 'observes' decoupling of accounting (often as a dysfunctional phenomenon) but fails to provide theoretical and empirical explanations of why accounting is decoupled from the operational core. This paper takes up that challenge. Using a case study of accounting regime change in a Malaysian company, this paper analyses how accounting regime was changed to overcome an instance of decoupling that management of the case company perceived to be problematic and, despite certain technological and managerial improvements, why the accounting regime yet remained decoupled from the control of core operations. Through an eclectic use of ANT, neo-institutionalism and political economy, it demonstrates that accounting remains decoupled from operational processes because of (1) the particular manner in which the accounting is constructed and enabled; (2) the ostensive characteristics of accounting objects around which performativity of accounting is defined; and (3) the organisational context, which involves certain 'political imperfections' that cannot be narrated within organisational apparatus of modernity. Accounting, being an apparatus of modernity, finds it difficult to codify such imperfections' and to offer an operational doctrine to govern the real business processes that are embedded within these 'political imperfections'. Hence, it remains decoupled from core operational activities insulating the 'political imperfections' with which business operates. As such, the thrust of the paper, and its primary contribution to the accounting litereture, is an illustrative case study that extends the theorisation of decoupling (cf., Weick, 1976, Meyer and Rowan, 1977; Covaleski and Dirsmith, 1983; Berry et al., 1985). Moreover, we bring political ideosyncracies of LDCs into our analysis and, hence, contribute to the set of accounting litereture that attempt to theorise accounting in LDCs. As the case story unfolds around a particular project of SAP implementation, especially 
in a less resourcefull context, it will also contribute to the stream of accounting research that documents organisational attempts of achieving functionalist aspirations of integration, standardisation, visibility and control at a distance through technological innovations such as ERP/SAP

However, the case presented in this paper involves neither a full blown ERP implementation nor a companywide planning system with any sort of strategic intentions. Instead, the case company launches into a partial adoption of SAP in a rather responsive reaction to a particular managerial crisis with a "panoptic dream of visibility and action at a distance" (see Dechow and Mouritsen, 2005 , p.729) that company managers attributed to SAP. Hence, in a technical sense, this case would not provide a perfect case of ERP or SAP implementation but offers a rich empirical story of accounting system change. In other words, eventhough the paper's empirical story unfold around a SAP implementation

Accounting decoupled

How and Alawattage

2012

A working paper. Please do not quote without authors' prior approval project, its primary focus is not on ERP/SAP implementation but on explaining why and how accounting remains decoupled from operational core. It nevertheless demonstrates the trust that managers place on computerised accounting packages as a mean through which they could enhance visibility and action at a distance, and how such accounting objects (re)define accounting regimes but fail to realise their presummed managerial functionalities of visibility, integration, standardisation and control.

The paper is organised as follows. The next section will do a brief reveiw of the current accounting literature on ERP/SAP with an aim to contextualise the paper within the alleged power of ERP/SAP packages to integrate otherwise decoupled organisational systems. This will be followed by research methods, the empirical story of accounting system change and, finally, a theoretical and empirical synthesis of why accounting remains decoupled, with special reference to the 'political imperfections' with which the businesses in LDCs often operate.

\section{Literature: functionalist dreams of visibility and control}

ERP has gained the attention of critical accounting and control researchers because of its alleged technological potential for unprecedented levels of organisational integration (see Davenport, 1995, 1998, 2000, McAdam and Galloway, 2005). This organisational integration is deemed possible because of ERP's integration of otherwise decoupled corporate information in one central database, which is then accessible and retrievable from different organisational positions (Dechow and Mouritsen, 2005). It is even suggested that "enterprise systems offer the first great opportunity to achieve true connectivity, a state in which everyone knows what everyone else is doing in the business all over the world at the same time" (Davenport, 2000, p. 5). For critical researchers, however, ERP systems should be examined not simply because of their "technological curiosities, but as vehicles through which fundamental questions concerning the nature of management control may be both asked and answered" (Chapman, 2005, p. 685). Accordingly, ERP has been conceptualised as a "steering mecha- 
nism", adoption of which imposes administrative interests on the organisation in place of processes which evolved over time following unique historical paths and trajectories (Dillard and Yuthas, 2006, p.220). As such,

\begin{abstract}
ERP systems impose radical changes on the everyday work lives of organizational constituents. ... The nature of social integration is transformed as communication is standardized and mediated through the system. Organizational goals and reporting language shift, changing perspectives regarding work objectives and subordinating objectives not in concert with those of the ERP systems. Employees adapt to these global and tightly interwoven changes to avoid the risk of sanctions in the newly competitive and downsized organization. (ibid)
\end{abstract}

\section{Accounting decoupled}

How and

Alawattage

2012

A working paper. Please do not quote without authors' prior approval

However, ERP has not always been assigned such a radical power. Dechow and Mouritsen (2005) raise the question whether it is possible or even interesting to integrate a firm's activities via its information systems, and whether this enables management control. Taking a case in which two Western companies pursued the integration of management controls through ERP, they demonstrate how the quest for integration is a concurrent, episodic and unending process. For them, ERP does not define what integration is but, by distinguishing between accounting logistical structures, only offers a techno-logic that conditions how control can be exercised. ERP makes data more accurate, available and open to sharing across an organisation, but hardly creates the "panoptic dream of visibility and action at a distance" (ibid, p.729).

The notions of visibility and distance are also at the centre of Quattrone and Hopper's analyses of two multinational organisations' attempts to implement ERP. Confronting the assertion that "ERP configurations can dramatically affect accounting controls and how actions are made visible" (Quattrone and Hopper, 2005, p.736), they address the issue of how ERP implementations achieve integration and influence how distances are created, managed and reduced. In one of the two organisations they investigated, ERP reproduced the existing structures of control at a distance through conventional accounting control, while in the other ERP was instrumental in instigating a constantly changing locus of 'minimalist' control; ERP, through its different configurations, can create different forms of distance and relations. The effect that ERP can have on management control is further echoed in one of their recent papers (Quattrone and Hopper, 2006). Taking the case of a large US multinational corporation, this time they argue that the ability to travel across organisations, in particular through SAP software package, stems from an absence which establishes a presence by mobilising and attracting other actors and technologies (ibid, p. 212).

Development of an IT-based management control system is a serendipitous process but evolves episodically (Hyvönen et al., 2008). It is suggested that IT solutions such as ERP can and do shape organisations' accounting realities, first by forcing accountants to study the logic of the solution, and second by challenging them to invent ways of coupling accounting with management reali- 
ties. Such alignment then shrink the distance between geographically separated units by gathering detailed data on the peripheral units and combining them into a "virtual mill" at the centre created by accounting reports (ibid, p. 59). However, akin to what Dechow and Mouritsen also observe, this virtual mill would not create their "panoptic dream of visibility and action at a distance" (2005, p.729) but an 'oligoptic' local totality which includes a propensity for errors, since its functioning depends on the existence of many information agencies and the connections between them (Hyvönen et al., 2008, pp.59-60). Nevertheless, standardised software packages such as SAP are deemed useful, not just because of their potential to manage distance through better visibility of the periphery, but also because they can be used to overcome resistance to change. It is suggested that such software packages enhance the "blind commitment to the system and reduce resistance to the new system" (Hyvönen et al., 2006, p.145)

ERP systems have been described as "modalities of structuration" (Caglio, 2003) because they are capable of offering interpretative schemes, norms and co-ordination and control facilities to create a symbiosis between accounting and other professional groups. Caglio (2003, p.146), for example, demonstrates how ERP was instrumental in technical accomplishments and professional expertise being "disembedded, lifted out of specific positions, incorporated into the IT systems and re-articulated across all the positions-practice incumbents who [could] draw upon the ERP in the accomplishment of their day-to-day activities". This empirical finding is akin to what Scapens and Jazayeri (2003) also find: ERP's potential to integrate, standardise, centralise and become routine opened up opportunities and facilitated changes in the role of management accountants (see also Chapman and Chua, 2003).

Two case studies of ERP implementation in LDC contexts (Jack and Kholeif, 2008; Kholeif et al., 2007) record implementation failures. Both of these case studies demonstrate how ERP implementations failed to achieve the intended integration and control functions. Jack and Kholeif's (2008) paper describes contests between ostensive definitions of the role of management accountant by the chief financial controller on the one hand, and politically performative definitions by the external funding agency of an Egyptian industrial modernisation programme on the other. Thus, in contrast to Caglio's (2003, p.146) observation that "ERP systems certainly provide management accountants with powerful modalities of structuration, which can be leveraged in order to provide new meanings to their activities, to increase the legitimation related to professional contributions and to the improvement of their power vis-à-vis the other stakeholders of firms", Jack and Kholeif's (2008) case is one in which "the role of the management accountants was returned to that of data custodian and information provider for others who controlled the organisation" (p.43). The 2007 paper by Kholeif et al. is an empirical extension of this observation. It addresses the same issue-why ERP has been unable to exert a significant change on management accounting-and finds explanations in the interplay between institutional pressures, institutionalised accounting practices, conflicting institutions, intra-organizational power relations and market forces. 
A salient theme in all these accounting research is the functionalist desire for integration across organisational functions and the role of accounting in that. While there are some academic reservations regarding the possibility and necessity of such integration (e.g., Dechow and Mouritsen, 2005), the managerial normativity seems to be that such integration is potential and beneficial. This functionalist ideology, especially as evident in our empirical data, is a well rooted "institutionalised myth" (Meyer and Rowan, 1977) among the managers. Although, for our academic eyes, decoupling seems to be a natural answer for inherent socio-political and technological contradictions within and between organisational and social systems, managerial orthodoxy has long been to see them as dysfunctional attributes that need to be mitigated through technological innovations.

\section{Accounting} decoupled

How and Alawattage

2012

A working paper. Please do not quote without authors' prior approval

\section{Research methods}

This paper is not exactly an outcome of any methodologically pre-planned research project; there never was a "rational-choice model" of methodology. Instead, there is a particular methodological story; a personal story along which different methods of data collection were made available. More than anything else, we have a methodological story to tell. A salient feature of this methodological story is the personal and culturally deep access to the site which offers us with ample opportunities to gain a deep insight into the actor worlds, to triangulate data we collected, and to revisit the site for data verification whenever it deemed necessary.

For many years, the first author and her close friend, a Finance Director (FD) to our case company, would catch up with each other every time the first author travels back to Malaysia. In December 2006, they met as usual through their 'yam cha'1 session to catch up. But this time, few minutes into their conversation, the FD started talking about his recent involvement in the SAP implementation in his company. For the next few hours of their 'yam cha' session, they talked about nothing else other than this SAP project. Full of excitement, the FD was telling the first author his genuine belief in the potential of SAP to integrate and control all branch networks and to improve the efficiency and effectiveness of the business operations. This conversation then lead to an "unofficial" arrangement that the first author would participate in the project as a "personal advisor" to FD so that, in return, she would be studying the project for her research purposes.

The first author followed the FD to the head office in Johor Bharu (JB). She was introduced to several senior level managers in the company whom the FD has close contact with regarding the SAP project. She was given permission to

1 The term 'yam cha' is a Cantonese term meaning to have tea. This term is also very popular among the Malaysians, but with a completely different context. The tea would take place late at night, usually between $11 \mathrm{pm}$ and 3 or $4 \mathrm{am}$. The people would go to the local street-side stores which serve drinks (both hot and cold) and some local delights. 
follow the FD around, to be introduced herself to other personnel, and to allow access to any documents and meetings deemed necessary to help with the project implementation and for her own research.

For the next four weeks (mid December 2006 to mid January 2007), the first author was observing the company's SAP implementation. During this period, the project was only at its infancy whereby there were still plenty of meetings and discussions among senior managers regarding the viability of this project and the expected time scale involved. The first author was not invited to any of these meetings but was able to converse with the FD with regards to the meeting contents. Furthermore, the first author was introduced to the accounts clerks who worked under the supervision of the FD. These "girls" (as the FD often called them) were very helpful in explaining how the "accounting things" work in their daily work routines at the head office. Even though this stay in Malaysia was relatively short, the first author managed to visit one of the S\&D outlets in Johor Bharu (JB). The S\&D manager explained to the first author how the manual accounting system works at the branch level, and granted permission for first author to freely converse with the S\&D accounts clerks so that she can gain more insights into their daily routines. In this way, the first author managed to gain an overview of the manual accounting system at the head office and the periphery (i.e. S\&D outlets). The "girls" were helpful in answering queries that "Miss" (the "girls" called the first author "Miss" to show respect as usual among Malaysians) put forward, showing her their work routines, filing system, accounting records etc.

Due to work and family commitments in the UK, the first author was not able to station long in the research site. Nevertheless, she continued to maintain close contact with the FD, JB S\&D manager and the accounts clerks through emails and Skype and telephone conversations to keep herself updated with the progress of the SAP project.

The first author made four subsequent site visits between July 2007 and December 2008, each stay lasted one- to two-month period. During those times, the company had went through several phases of transformation from testing to rolling out the SAP package progressively starting from the head office and S\&D outlets in JB, Selangor, Pulau Pinang to the final S\&D outlet in Pahang. During these visits, interviews have been conducted with the S\&D managers of each outlet. Each interview ranged between 30 and 40 minutes. Some managers have agreed for the conversations to be recorded while others preferred not to. Under those circumstances, notes were taken during the interviews and were transcribed into complete versions when the contents were still fresh in mind. The "girls" however, were more reserved to talked to the recorder, but informal conversations during lunches and late night 'yam cha' sessions were very effective with them. "Girls" were more relaxed and chatty as a group outside their work settings. So, first author formally interviewed managers, had informal conversations with FD and accounting clerks, observed (and helped) what they were doing, attended their meetings (mainly as non-participant observer but with some inputs when she was invited to offer her opinion), browsed through 
documents and gained a good understanding of how the SAP project went on and what happened to the organisation and its actors during that.

A detailed timeline and research activities carried out during these field visits have been summarised in the Appendix 1.

Nevertheless, for us, methodology means the totality of the approaches through which this paper is produced. It includes not only the data collection methods we deployed, but also the theoretical premises upon which data were interpreted and conclusions were drawn. Data collection methods deployed were contingent very much on the social and cultural connections between the first author and the people at the site. Theoretical choices, on the other hand, were driven by the analytical focus, which is on two interrelated issues. First is empirical: how an accounting regime was changed to overcome an instance of de-

Accounting decoupled

How and Alawattage

2012

A working paper. Please do not quote without authors' prior approval coupling - a particular set of managerial politics and episodes that transformed the accounting system. In this regard, what we needed is, not an 'interpretive' theory to conclude upon our findings, but a theoretical framework that can organise our story into a meaningful set of episodes. Although it provides only a partial explanation of why accounting remains decoupled, Callon's (1986b) "sociology of translation", most importantly its phases of translation - problematisation, interestment, enrolment and mobilisation - comes handy in storytelling, especially in terms of its capacity to capture the micro politics of how accounting is constructed, enabled and how its performitivity is locally defined.

The second issue is interpretive: why accounting remains decoupled from the operations. An account of how accounting is constructed enabled and how its performitivity is locally defined can only offer a partial explanation to this issue. Political and institutional rationales of decoupling lie beyond these micro politics. They are rooted in 'political imperfections' with which the company operate; decoupling is demanded by these political imperfections of the operations. As such, our analysis goes into certain institutional and political economic dimensions of the business context within which decoupled accounting is (re)produced and institutionalised. To this end we draw eclectically on other theoretical frameworks, with special reference to Myer and Rowan's (1977) notion of "institutionalised myths".

\section{The story: transformation of accounting regime}

\section{Episode 1: Accounting as a localised practice}

The story involves a medium-sized company in Malaysia (LC for anonymity). LC was established in 1999 with its sole office located in the city Johor Bahru (JB), which is located in the most southern part of the Peninsula. ${ }^{2}$ The company

2 Malaysia is composed of two regions-Peninsular Malaysia and East Malaysia-separated by the South China Sea. Peninsular Malaysia comprises the states of Perlis, Kedah, Pulau Pinang, Perak, Kelantan, Terengganu, Pahang, Selangor, Negeri Sembilan, Melaka and Johor, while East Malaysia consists of the states of Sabah and Sarawak. See Appendix 2 for geographical presence of the company in Peninsular Malaysia. 
started out as a wholesaler of building materials to local builders around the JB area. Its initial success, however, rested pretty much on the 'political capital' of the owner. From its beginning the company was able, through political contacts, to secure major government building projects, and gradually turned itself into one of the major building materials suppliers both to local builders and to the local government. By 2003, its growth was so "remarkable" that it expanded the business by launching into manufacturing building materials. By mid-2007, they had established three manufacturing sites (in Kedah, Selangor and JB) and Sales \& Distribution (S\&D) outlets spreading across the whole of Peninsular Malaysia. They employed a total of 80 staff (excluding casual labour which the company heavily employs in its manufacturing sites without formal employment contracts) and annual turnover averaged RM 25 million.

\section{Accounting} decoupled

How and

Alawattage

2012

A working paper. Please do not quote without authors' prior approval

The growth of the business was understood more in geographical terms than in terms of transaction volume: "we are now everywhere in the Peninsula," boasted a manager. However, despite the unification of its operations under a single company name, logo, standard name boards and a legal existence as a private limited liability company, this geographical expansion was more like a sequence of giving birth to new family members with their own independent commercial (and political) existence, which asserted a 'corporate identity' through occasional ceremonial rituals of accounting. For example, S\&D outlets were not governed by a set of corporate policies and procedures. Each S\&D outlet decided its own pricing, debt collection, wages and also 'political payments' and capitalised upon the political contacts that regional managers had developed within the local political patronage. By its nature, especially given the significance of local government agencies and politicians as the main customer base, the enterprise was rather political and this dependency on the local political patronage demanded a high operational independence (and secrecy) for local S\&D outlets, minimising the possibility of stronger operational integration through a set of centralised corporate policies. Thus, the company we are discussing here was indeed a network of loosely coupled entities, the integration of which into a company identity mainly took place through accounting.

This means, as a network of loosely coupled entities, the corporate existence was reproduced through symbolic acts of balancing conflicting interests: operational autonomy or vertical decoupling of subunits on the one hand, and integration into some sort of corporate identity (with minimal control) on the other. The company's accounting regime, at this phase of its history, was the configurative outcome of this tension between integration and dis-integration. And, the company's accounting system consisted of a set of autonomous accounting entities, more or less independent of each other and of the centre (i.e. Head Office). For example, each S\&D outlet had its own independent system of accounting, with a certain degree of isomorphism (see DiMaggio and Powell, 1983), which featured a high degree of similarity between the systems but no interdependency or integration. An accounting clerk described what and how they did: 
Transactions are recorded manually in the books and ledgers, which are kept in the filing room. We also have a separate file (physical) for every customer, every supplier, and also for all types of expenses. They are all there in the filing room, nicely sorted, and can be retrieved in less than a minute. ... I enter all vouchers and invoices to the ledgers every day, and store them neatly. See that chart on the cupboard, that's the filing index. Try it: EVEN YOU can easily find any file you want just in a minute... We have a separate bank account in the local branch of the bank. Every day we deposit our collection in that account and pay our expenses out of it. When Head Office wants some money they should contact our manager here, and he either transfers money or sends a cheque. Each week, we pay to Head Office whatever dues we owe for the supplies we receive from them. Similarly, when we need money from Head Office, we telephone them and they transfer that to our account. . . . Yes, I think so; all outlets do business like this.

\section{Accounting} decoupled

How and

Alawattage

2012

A working paper. Please do not quote without authors' prior approval

The "boss" of a sales outlet (as he was called by his staff) reinforced this point:

We manage our own outlet, we have our own customers. ... We make them (politicians) happy in our own way, and they know how to keep us happy. You have to be one of them to keep your business with them running. ... I mean, it's all politics. ... They don't want to do business with people that they don't know and can't trust.

Accounting between the periphery and the centre took two different forms. The first was operational: accounting for logistics from the centre to the periphery. As soon as the company launched the manufacturing of building materials, each S\&D outlet had to order the majority of its supplies from the company's manufacturing sites. To eliminate competition between these manufacturing sites in selling their goods to S\&D outlets, the company sought to coordinate all logistics through Head Office: the manufacturing sites were directly controlled from the HQ in JB. Of the eight S\&D offices, the one in Kuala Lumpur is regarded as the S\&D head office: it collected orders from all other S\&Ds across the Peninsula and communicated these to HQ in JB, which then distributed the orders to the manufacturing sites nearest each $S \& D$ office. For example, there are two S\&Ds in Pulau Pinang, on the north side of the Peninsula; the manufacturing site closest to these S\&Ds is in Kedah, also on the north of the Peninsula. Once the materials ordered were ready, the manufacturing sites would deliver them directly to the S\&Ds that had ordered them. HQ in JB then billed the S\&D head office which in turn billed the other S\&Ds for the materials ordered. Accounting (i.e. symbolic acts of ordering and exchanging information in this instance) took place first through (in)formal telephone calls and emails followed by "delivery of (source) documents once they are ready". This mediating act of the centre between the manufacturing plants and S\&D outlets of course achieved a certain degree of operational integrity, but it still allowed the S\&D outlets to run as independent businesses that 'transacted' with the other units through the centre. 
The second form was ritualistic: end-of-year communication of information for corporate financial reporting. HQ would send a standardised Microsoft Excel spreadsheet (called ConsolEx) to each S\&D. ConsolEx usually contained accounting categories needed to prepare income statements and balance sheets for the company as a whole. The S\&Ds were required only to fill in these categories with figures obtained from their own accounting records.

\section{Accounting} decoupled

How and

Alawattage

2012

In order to provide the aggregate figures (account balances) for ConsolEx, accounting clerks at S\&D outlets also maintained, in stand-alone computers, a spreadsheet-based (Excel) set of accounts which basically duplicated the manual accounting system. The response from an account clerk said it all:

Excel is all we need. They [HQ] ask us to put the totals in their spreadsheet, so we thought 'why not maintain our accounts in a spreadsheet', right? We have an accounts template in a single file with individual accounts and account codes. We record daily transaction 'totals' in these accounts and can extract a list of account balances at any time. Every month I open a new file using the same template, transfer closing balances from the previous month's file and continue recording transactions for the new month in the new file. So, I have twelve files for the whole year (this is of course a straight forward duplication of what they do with the non-computerised accounting system). In that way, I can extract not only figures but also annual totals and balances. Then we copy and paste the total from our side to their ConsolEx, depending on what they want that year.

With such a reporting structure, accounting does not appear to have been a means of 'control' but of 'memory', from which a unified corporate image could be extracted. Although with a high degree of isomorphism between them, each of these S\&Ds was free to design a localised accounting system (manual), of which 'totals' are duplicated in Excel. Each S\&D outlet had its own Excel-based accounting templates (which people in Head Office called S\&D Excel), which were not 'networked' to one another. As such, LC had eight slightly different versions of S\&D Excel maintained separately by individual S\&D offices. According to our observations, accounting clerks at each S\&D outlet had plenty of freedom to decide on issues such as the layout of their own S\&D Excel, how frequently transactions were recorded, which accounts were created and used and how they were coded. Accounting clerks often sought the advice from the S\&D managers (rather than from accounting personnel in the Head Office) as to which expense categories "special or problematic payments and expenses" were to be categorised. In many instances, it was the sales people who directed the accounting clerks as to which pre-existing accounting categories certain transactions should be classified and recorded in the accounting system. Accounting protocols and classifications never existed as a set of operational doctrines to formalise and regulate the actual carrying out of day-to-day transactions. Of course there were some well understood and apparently followed accounting rules and protocols such as "a source document should be raised for every
A working paper. Please do not quote without authors' prior approval 
transaction" and "audit trails should always be maintained", which nevertheless seemed to be doctrines to govern the accounting function itself. At their best they could only operate as internal checks to minimise the frauds and errors (as FD himself acknowledged). As common not only in the construction industry but also in many other Malaysian industries, the core operational functions of sales (including bidding for local government contracts) and production (including a greater use of casual labour, for which no formal individualised labour contracts ever maintained) have always been handled through local cultural-political patronage (cf. Alawattage and Wickramasinghe, 2008, 2009).

Thus, decoupling was demanded at the periphery as an operational doctrine through which political necessities of local business could be managed. Ac-

Accounting decoupled

How and Alawattage

2012

A working paper. Please do not quote without authors' prior approval the business from its "formal" institutional setting and is "considered proper, adequate, rational and necessary" and is "incorporated to avoid illegitimacy" (see Meyer and Rowan, 1977, p.345). Accounting personnel was primarily considered, by themselves and by others, as the 'official scorekeepers' who have answers for formal queries of 'others' including customers about the "status of various things" (such as amount due from a particular customer or amount owed to suppliers and manufacturing sites). According to an accounting clerk:

My managers have to approach me if they want the itemised details of certain accounts that we hold, or the total amount for each account, or for each category. Whatever they want, they just tell me, and I can produce it for them in seconds. I know everything there is in the sheet [S\&D Excel]. (She then broke into proud laughter.)

So was the accounting system in LC, where accounting was a institutionalised myth that performed a ceremonial task of portraying the organisation as a "formal" structure that keeps "official records" of operational activities through bookkeeping. Importantly, this officiality and formality of the organisation is maintained through bookkeeping. It is interesting to see that, especially in an academic world of accounting where we have been busy attributing all sort of strategic and operational importance to accounting, bookkeeping has always been the primary function of accounting in our Malaysian company. Could accounting gain such an operational and strategic importance of integration, standardisation and networking when it moved into a computerised system? We will discuss this in the next few sections.

\section{Episode 2: problematisation - projecting decoupling as a mana- gerial problem}

An accounting regime is historically contingent and evolves from one state to another either by responding to historically specific events internal or external to the system or as a consequence of inherent contradictions in the system (see also Alawattage and Wickramasinghe, 2009). The tension between periphery 
and centre in LC has always been a systemic contradiction of this kind. Decoupling between the centre and the periphery and its corollary that the centre lacks the visibility of the periphery have long been a "headache" for managers at the centre, especially for the FD, who as a qualified accountant has always had a high aspiration for an organisation governed and managed by accounting. He has long "sensed" the problem with these "weaknesses in its internal controls[:]...too much freedom and inconsistency at the S\&D outlets", but had neither time nor managerial priority to dig into the matter and to initiate a change until a particular incident occurred in one of the sales outlets. Had the manager of that sales outlet not unexpectedly resigned from the job (along with two other employees, one of whom was the accounts clerk) and commenced his own business competing with the branch, the centre "would have still been

We are not multinational, so the thought of having ERP in the company was too much. We kept asking ... Is this necessary? Will this be too big for us to handle? It took a lot of effort to persuade our boss (the Chairman) that this was what we needed. ... it was the fear, yes fear that the same (incident in the sales outlet) would occur in other places that made us go with the ERP project despite all those uncertainties about its success.

This particular incident was 'historic' in the sense that it provided the impetus to bring the accounting system to the forefront of the managerial agenda for transformation. The centre's inability to find out exactly what had occurred at the outlet concerned, especially how much money had been misappropriated, ${ }^{3}$ was understood as an accounting problem. It created general acceptance across the organisation of the inability of the existing accounting regime to regiment the periphery: of the incapacity to render the periphery properly visible to the centre and, thereby, to hold the periphery accountable and governed. In consequence it became obligatory that top management "do something to prevent the recurrence of such an event". It also became obligatory that "people at the sales outlets should work together with Head Office to implement a better system of accounting", if only to show that "we should not be seen as a set of crooks who show no commitment to the common good of the company as a whole". The result of this 'incidental' arousal of consensus between the centre and the periphery was a managerial agenda to change accounting.

As such, a crisis was perceived and change was deliberately sought to resolve it. A "change management programme" was set up and led by the FD, whose expertise is respected and who was accepted as the best to lead it. He was en-

3 General discussions on this issue always presumed that there had probably been significant misappropriation of money from the branch under the manager who left the business. As a manager in Head Office put it, "otherwise he could not have had enough capital to start his own business. He was just nobody before joining this company ... the salary here, by itself, would not make him rich enough to start his own business. I don't know (or rather, don't want to tell you what I think about) where he got that money from." 
trusted to bring the necessary change to the system. Because others perceived themselves relatively ignorant of "accounting matters", this change management agenda was left more or less the sole property of the FD. So, he busied himself in dealing with the "accounting system change", which he understood as "of paramount importance to the company's future prospects". He projected this belief in "paramount importance" to others through deliberations in staff meetings, memos, and also through various email attachments that emphasised the potential of SAP, which is the approach he finally selected to resolve the accounting crisis. Through these discourses he not only convinced others of the importance of a new technology but also located himself as a power figure by redefining himself as a "change agent". When this discursive repositioning was supplemented by "positive leadership traits" that others in the company seemed

\section{Accounting} decoupled

How and Alawattage 2012

A working paper. Please do not quote without authors' prior approval to appreciate highly, he had been enabled to make changes that he thought could resolve the perceived crisis of decoupled accounting.

It is interesting to observe that there was an evolution in how the "crisis" was perceived and defined over the period in which SAP was installed. The initial incident in one sales outlet appeared to be a crisis of greedy and opportunistic behaviour by some people at a particular place on the periphery. Later, relegating the personalities involved in this particular incident into the background, the crisis was gradually translated into a problem of accounting that emphasised the incapacity of the centre to monitor the periphery: an instance of vertical decoupling which is now begun to be seen as an accounting problem for which one should seek an accounting solution. Accordingly, SAP was brought in as the appropriate solution and the problem was redefined again in line with the properties of SAP itself. That said, the "crisis" was a dynamic construction subject to continuous reinterpretation and redefinition through ongoing dialectics between the solution and the crisis: they each evolved in reference to the other. As such, the programmed functionalities of SAP redefined the particular crisis as a problem of synchronising accounting activities across the network. At this stage, the FD spelled out the crisis as follows:

This is serious! We have eight systems out there ... all operating on their own. They use their own systems of classification. In some, unbelievably, telephone bills are marketing expenses while in others they are administrative expenses. We never bothered about such fine details but demanded the totals for financial statements.. . . yes, for example, we asked them the total of marketing and distribution expenses and they gave a figure. We never questioned what it included, as far as corporate profit can be accurately calculated.... What we need to do right now is to bring all these into a unified coding system and make sure that things are done in a similar manner across all the sales outlets. That's where SAP comes in very handy. Once weve got SAP running across all the sales outlets, we'll have one single accounting system, not eight different systems out there. 
The indispensability of SAP was asserted through discursive redefinition of the crisis to match the pre-defined functionalities of the program, so that implementation of SAP became perceived as the indispensable solution to the perceived crisis of decoupled accounting. At this phase of the accounting regime change, "standardised", "integrated" and "networked" have become effectively discoursed and idealised characteristics of a "better managed company". SAP and its associated literature have been instrumental in bringing such "institutionalised myths" in the corporate thinking. As such, the status quo was problematised vis-à-vis these "institutionalised myths" (see, Meyer and Rowan, 1977) brought in through SAP and FD's expert discourses.

\section{Episode 3: interestment - projecting company as a "fish tank"}

Accounting decoupled

How and Alawattage

2012

A working paper. Please do not quote without authors' prior approval

Accounting system associates heterogeneous entities and it may construct a plurality of different and incommensurate worlds (cf. Callon, 1986a). However, amid such heterogeneities and pluralities, the accounting actors construct an alliance through (re)definition of their roles. This defines their identities, the roles they should play and the nature of the bonds that unite them into a coherent system. It is such roles and relationships that define the accounting system. An accounting regime, which is a particular historical phase in the evolution of accounting systems, is thus defined by the particular roles that different actors assume or are forced to assume and particular relationships (or distances) that they maintain with one another. Nevertheless, such enrolments are neither pre-given nor an external reality that actors attempt to understand and capture (see Callon, 1986a, p.24). Instead, they evolve in line with the power struggles between different actors in the actor-network, within which there often exist clear differences between actors in terms of their relative endowments of capital: especially cultural and symbolic forms of capital (see Bourdieu, 1986). Thus, an accounting regime becomes historically dynamic as actors continue to redefine the roles they assume within the actor-network. This redefinition of roles and relationships constitutes a process of translation: a process of attributing to actors with different identities, roles and associations.

Such a process of translation may be led by a dominating actor, a "translatorspokesman" (sic) as Callon (1986a) calls it, capable of constituting the roles of other actors. $S /$ he is thus the spokesperson of the entities s/he constitutes (see Callon, 1986a, p.25). S/he earns the capacity to represent and put into expression the desires, interests and mechanisms of operation of others in the actornetwork. In this case, the FD was this translator-spokesman. As part of the SAP implementation process, a project team was established. The team was led by the FD but supplemented by an external consultant who brought a small team of IT personnel with him. Other team members included the S\&D managers and accounting clerks. Setting up this team was critical for the implementation as it was the social and institutional platform on which the FD could establish himself as the 'translator-spokesman'.

His translator-spokesman role was explicit in his associations with others. He was speaking on behalf of the company, its long-term interests, its employees 
and explicitly took on the translator role (which he often described as the "strategic leadership role that the company expects from me") to transform the company to a "better managed one". Accordingly he believes, states and attempts to convince others that:

[f]rom top management to the accounting clerk, everyone in this company should abide by a clear set of accounting policies and every transaction should be recorded and documented. This is a basic principle of internal control that I was taught during my Chartered Accountancy training. And this principle is a fundamental pre-requisite for a better managed company. That's how and why we become accountants, by abiding by the rules and to implement such rules for the betterment of everyone. ... We are all like fish in a fish-tank. The tank is the company and we are the fish. If the tank is damaged and the water leaks out, that is the end of the fish. For me, finding another tank would not be difficult at all, but for you, I know, it would be really difficult. . . . Everyone in the company should therefore understand that it is in your own interests for us to bring in a new accounting system: to protect the company and to protect everyone's job. So you should not see this as a new problem. It is a solution, but becomes possible if and only if everyone here fully supports it and works to get it implemented. (FD during a training session)

Interestment was a discursive process through which a set of "institutionalised myths" are translated into a set of organisational propositions that organisational actors collectively begin to believe as indispensible. Empowered by the acquired role of translator-spokesman, and mobilising his cultural and symbolic capital as one of the most educated and professionally trained managers, FD thus created an alliance between the centre and the periphery for "everyone's common good". He got accounting clerks and others 'interested' in the activities required to translate their local accounting system (especially expenditure coding and classification) to the coding system proposed by SAP. Although their initial reaction was resistant, especially owing to the additional workload during the transition process and ignorance and misconceptions of SAP, accounting clerks at the sales outlets were easily brought to the project by employing a combination of monetary incentives (overtime payments, which had never been offered in this company before), subtle punishments (ridicule) and official threats of job losses for those failing to learn SAP. A series of training programmes was put in place. The first programme aimed at introducing SAP to all the clerks. Each of them was provided with a handbook which described SAP characteristics, functions and provided problem-solving tips. The next programme involved specialised functions such as human resources, finance, purchasing, sales and others. Clerks were grouped by job function and required to attend training related to particular functions.

In this manner, by December 2008 the SAP was up and running, and had been implemented "successfully" from the points of view of the FD and the accounting clerks. This success was fundamentally attested by the outcome that "now 
we have one accounting system across the company, not eight different systems where each sales outlet had its own system of recording transactions" (FD). For an accounting clerk, the "SAP project was not bad at all, though we initially thought it could mean more trouble for us. Now we know what it is and we are better linked with Head Office. Bosses are happy about us and we even had a little bit of salary increment in gratitude for our support." For the actors involved, it seemed (especially at the rhetorical level) that the presence of SAP symbolises a new accounting regime capable of synchronising accounting activities across the company, on a more frequent basis (weekly, rather than annually as was the norm before SAP). The FD has commented:

Now I am in a position to create financial statements at any time of the year, up to date. At any time I have full accounting information from the branches for that.... [previously] we used to get this once a year only, through what [the ConsolEx] I sent to all branches at some point in December. . . A Accounting clerks are required to feed information to SAP every week and they of course do it nicely. I am really happy about their work. So I gave them a salary increment as well, not much but good enough for them.

Interestment involved a series of multilateral negotiations which kept the relevant actors regarding themselves as better off after the proposed changes and also kept their active support for the project of reforming the way they had hitherto performed accounting activities. By these means, a set of changes was made to the way that accounting is performed across the network. SAP, as a non-human actor, provided the necessary technical templates and protocols for this reorganisation (i.e. synchronising) of accounting activities.

\section{Episode 4: Enactment and redefinitions}

Human actors across the company were bought into the new alliance with relative ease. Their involvement in the project team made them see themselves as instigators and therefore having responsibility to encourage the acceptance of SAP and to see the implementation process through to success. The problems of SAP' more or less became 'everyone's problem' rather than one exclusively for top managers or the 'company', and SAP became a pet that everyone had to play a part in taming.

When the system went live, the clerks had to enter old data into the new system manually, creating different accounts, assigning account codes, creating customer database etc. The process was only halfway through when the hardware configurations became unstable and the system could allow no further data input until another hardware upgrade took place. At a later point, there was a system crash and the team had to spend almost a day trying to reboot the system. When two or more clerks logged on to the system at the same time, and worked on the same interface, the system would slow down or even crash. The team had to suspend the testing and carry out investigations in order to identify the root cause of this IT instability. After a series of trials, disruptions, 
failures, work and rework, the team managed to solve the problems, but not without compromise. The newly improved system still could not reliably cope with multiple peripheral loggings to the same interface without compromising on speed and the potential risk of system crashes. For the IT personnel, these customisation failures were a problem not just of SAP but also of lack of capacity in the hardware infrastructure within and beyond the company, including the capabilities of distant actors such as internet service providers. Ultimately, the team could not get the SAP fully performing to its technical potential. Instead, they settled for a workable solution involving two modules (accounting and HRM), dropping operational and logistical aspects of the system altogether. However, neither the factory nor the S\&D managers were much concerned about this non integration of factory operations and logistics. The FD was still happy, since "we have only one accounting system, not eight different systems out there ... and I can now produce all financial statements and reports I need

Accounting decoupled

How and Alawattage 2012

A working paper. Please do not quote without authors' prior approval at any time of the year" ${ }^{\text {" }}$. Operational integration and monitoring has never been a burning managerial issue.

Despite the FD's claim that the SAP implementation had been successful, there is little visible evidence that it resulted in a "remarkable change" to the accounting regime, especially at the periphery. It did not transform or replace the original accounting system but simply provided an incremental improvement to it by supplementing and synchronising the old one. S\&D outlets still rely heavily upon the manual accounting systems. Since operational dimensions of transactions are not automated through any computerised transaction-handling devices (such as scanners or integrated tills), sales and accounting personnel at the S\&D outlets still record transactions manually in source documents and transfer them to the system each day. In other words, the accounting regime still remains "offline", as one IT consultant put it. However, LC now has a synchronised system of accounts, transaction categories, customer codes and supplier codes, allowing a uniformity between all the sales outlets to be presumed. Two features of the previous eight-fold system, S\&D Excel and ConsolEx, have disappeared.

The resulting change in the accounting regime can be understood in two interrelated dimensions. First is the actor transformation of the accounting regime, by which we mean the transformation of the relational identities of the actors. The second is the processual transformation, by which we mean the transformation of the way that transactions are accounted for and reported to Head Office. Table 1 below summarises the resulting actor transformation in the accounting regime, and Figure 1 summarises the resulting processual transformation of it. Taken together, these two illustrations provide an account of the accounting change that took place in LC during our fieldwork. SAP imple-

4 This claim of the system's capacity to generate financial statement at any time is rather an overestimation due to the fact that the existing SAP has not effectively incorporated logistics and inventory into the system, other than recording purchases. The system cannot tell him the inventory figures at any time of the year. Hence, until the next annual stock taking, the system can only generate profit and loss accounts with no inventory adjustments, with which the FD seems to be rather happy. 
mentation has reasonably improved the efficiency with which the accounting function itself operated but failed to register any new controlling functions or identity to offer an operational doctrine for the core-business operations. It has reasonably minimised the vertical decoupling between the accounting at the head office and accounting at the periphery, and constructed an integrated accounting system that made the key accounting actants contented about the newly gained capacity of the accounting to communicate the "official imagery" more effectively and efficiently. However, FD's panoptic dreams of visibility and control have always been confined to the intra dynamics of the accounting actor network. As such, the redefinition of the accounting has never been geared to penetrate the non-accounting actor networks that deal with operations in the market and the manufacturing sites. They have always run on the political capital and patronage relations in the local markets and communal and casual labour relations (without formal employment contracts for labourers, and hence with a bare minimum of statutory payments, as many other firms in the field do) around the manufacturing sites. Especially in the manufacturing sites, highly labour intensive manufacturing was driven by the availability of law paid casual labour, mobilisation of which is highly dependent upon the communal patronage of the site supervisors. Non-accounting actor networks have always been left decoupled from the 'formalities of accounting. Accounting never controlled the way that non-accounting activities are performed or provided a decision making rationale or tools for them. It simply facilitated the non-accounting actants only through clarifying the financial status quo of their customers and dealers, while the credit and other pricing decisions have always based on non-accounting rationales of political capital and patronage (which are not necessarily non-economic). More than anything else, what accounting does is primarily to 'translate' the performative outcomes of the 'unofficially performed' non-accounting actor network into a set of 'official' narratives that can legitimately be read within the apparatuses of modernity, especially of the official face of the political state. 
Table 1: Actor transformation of the accounting regime

\begin{tabular}{|c|c|c|}
\hline Artefact & $\begin{array}{l}\text { Accounting regime before } \\
\text { SAP project }\end{array}$ & Accounting regime after SAP project \\
\hline \multicolumn{3}{|c|}{ Human actors: } \\
\hline FD & $\begin{array}{l}\text { Rather detached from the periph- } \\
\text { ery and concentrated mainly on } \\
\text { the 'accounts in the head office, } \\
\text { bank negotiations, tax returns } \\
\text { and corporate secretariat services' } \\
\text { Played an analyst role and heavily } \\
\text { dependent upon the informa- } \\
\text { tion provided by the S\&D outlets } \\
\text { through ConsolEx, which was the } \\
\text { primary means of gathering data } \\
\text { from the periphery. Head Office } \\
\text { never assumed a controlling, but } \\
\text { rather a service role, and so did } \\
\text { the FD. }\end{array}$ & $\begin{array}{l}\text { Transformed into a translator-spokesperson } \\
\text { and now plays a leading role in integrating } \\
\text { the periphery with the centre. Frequent } \\
\text { contacts with accounting personnel in the } \\
\text { periphery, and the identity has been rede- } \\
\text { fined through these contacts away from the } \\
\text { analytical role played earlier. Empowered } \\
\text { not only by the frequent and more accurate } \\
\text { data flowing from the periphery through } \\
\text { SAP but also by the political alliance he has } \\
\text { now created with his "new men and women } \\
\text { at the periphery". Acts as the central contact } \\
\text { point and authority on 'SAP issues and mat- } \\
\text { ters. His new identity is central to the actor- } \\
\text { network of accounting regime. Sources of } \\
\text { his power have moved beyond his technical } \\
\text { expertise and professional accreditation to } \\
\text { network politics. Now a man on the move } \\
\text { with "frequent branch visits". }\end{array}$ \\
\hline $\begin{array}{l}\text { Accounting } \\
\text { clerks }\end{array}$ & $\begin{array}{l}\text { Attachment was more to the } \\
\text { relevant S\&D outlet than to the } \\
\text { company or Head Office. Only ad } \\
\text { hoc, incidental and annual inter- } \\
\text { actions with Head Office through } \\
\text { ConsolEx. }\end{array}$ & $\begin{array}{l}\text { Attachment is more to Head Office (FD) } \\
\text { and they now work as the main representa- } \\
\text { tive of Head Office in the S\&D outlets. Fre- } \\
\text { quent data feeding to Head Office through } \\
\text { SAP and informal political alliance with the } \\
\text { FD. Seem empowered by this new technol- } \\
\text { ogy and alliance. }\end{array}$ \\
\hline $\begin{array}{l}\text { S\&D outlet } \\
\text { manag- } \\
\text { ers and } \\
\text { manufac- } \\
\text { turing site } \\
\text { managers }\end{array}$ & \multicolumn{2}{|c|}{$\begin{array}{l}\text { Have never been actants of the accounting network, but 'trans-actants' of it. Less } \\
\text { concerned with 'accounting matters' than with 'making customers happy'. Politically } \\
\text { active with local political patronage structures to assure continued business with } \\
\text { the government and other large corporate customers. Identified themselves as the } \\
\text { "people who run the real business". Interact with accounting personnel incidentally } \\
\text { and non-routinely in response to customer inquiries and expense handlings. Little } \\
\text { respect for accounting protocols although occasional reliant upon accounting } \\
\text { information to "know account status of my dealers and customers". Seem not to } \\
\text { trust or value accounting information in their day-to-day decision making but rely } \\
\text { more on gut feeling and knowledge of people: "I know whom to trust and deal with } \\
\text { from my own experience more than through the books (i.e. accounts). They may } \\
\text { be not paying bills on time but that does not mean that they are not reliable. They } \\
\text { do have to deal with and scrawl through all those government protocols. They take } \\
\text { time. Don't they?" SAP has not made a noticeable difference to their day-to-day } \\
\text { patterns of operation, except that they seem "pleased to see that I now have far } \\
\text { fewer complaints from the customers that their recent payment has not yet been } \\
\text { acknowledged" (S\&D outlet manager). }\end{array}$} \\
\hline \multicolumn{3}{|c|}{ Non-human actors } \\
\hline $\begin{array}{l}\text { Financial } \\
\text { statements }\end{array}$ & $\begin{array}{l}\text { Capable of being produced only } \\
\text { once a year as an annual ritual. } \\
\text { Though not used extensively } \\
\text { for decision making or control } \\
\text { purposes, compilation of these } \\
\text { statements was understood to be } \\
\text { the most compelling evidence of } \\
\text { the value of the accounting-actor } \\
\text { network. Accounting was there } \\
\text { mainly to produce this. This } \\
\text { 'false consciousness' discursively } \\
\text { underestimated the operational } \\
\text { role of accounting, especially in } \\
\text { customer handling/cash collec- } \\
\text { tions. }\end{array}$ & $\begin{array}{l}\text { Now capable of being extracted at any time } \\
\text { "at worst with one week's delay in data } \\
\text { feeding". However, there is no remarkable } \\
\text { change in the format and content of the } \\
\text { reports nor in the uses they are put to. Still } \\
\text { mainly used as a symbolic means of pro- } \\
\text { jecting a corporate identity to the outside } \\
\text { world. }\end{array}$ \\
\hline
\end{tabular}

\section{Accounting} decoupled

How and

Alawattage

2012

A working paper.

Please do not quote without authors' prior

approval 
Table 1: (continued)

\begin{tabular}{|c|c|c|}
\hline ConsolEx & $\begin{array}{l}\text { Was the main mediating instru- } \\
\text { ment or the boundary object } \\
\text { between Head Office and the } \\
\text { branches, acting to synchronise } \\
\text { the differences between relatively } \\
\text { independent accounting systems } \\
\text { across the branches. }\end{array}$ & No longer used after SAP. \\
\hline S\&D Excel & $\begin{array}{l}\text { Used to create an abridged 'digital } \\
\text { copy' of the manual accounting } \\
\text { system to facilitate the annual } \\
\text { rituals of communicating 'finan- } \\
\text { cial statement information' to } \\
\text { Head Office. }\end{array}$ & No longer used after SAP. \\
\hline $\begin{array}{l}\text { Ledger ac- } \\
\text { counts }\end{array}$ & $\begin{array}{l}\text { Were always been the primary } \\
\text { means through which day-to-day } \\
\text { transactions were recorded by the } \\
\text { accounts clerks. } \\
\text { Before SAP, they existed only } \\
\text { in manual form in traditional/ } \\
\text { standard 'ledger books' and } \\
\text { 'account sheets' readily available } \\
\text { from suppliers of accounting and } \\
\text { office documents. Since no final } \\
\text { accounts or trial balance were } \\
\text { prepared at branch level, no inter- } \\
\text { nal balancing between accounts } \\
\text { was carried out at branch level. } \\
\text { However, a separation between } \\
\text { recording and actual handling of } \\
\text { money was strictly maintained } \\
\text { as an internal control procedure, } \\
\text { since "that is something that } \\
\text { external auditors often look into". } \\
\text { These accounts were the frequent } \\
\text { and ultimate source of reference } \\
\text { to verify amounts due from or to } \\
\text { customers and suppliers. }\end{array}$ & $\begin{array}{l}\text { Continue to exist in manual form as the } \\
\text { primary means of day-to-day recording of } \\
\text { transactions. Once or twice a week these } \\
\text { manual ledger data are manually fed (of- } \\
\text { fline) into the SAP by accounting clerks. } \\
\text { These ledger accounts exist both in manual } \\
\text { and digital form, and the digital form (i.e. } \\
\text { the SAP database) now forms the reference } \\
\text { point for most customer/supplier inquiries } \\
\text { with occasional reference to the 'real ledger'. } \\
\text { The paper-based manual ledger is still seen } \\
\text { as the 'real ledger' and SAP is there to trans- } \\
\text { late this into virtual form, to synchronise } \\
\text { ledgers and make the data readily accessible } \\
\text { across the company. } \\
\text { However, the "old system of accounts and } \\
\text { their codes have been modified and updated } \\
\text { to tally with the SAP" and, as a result, all } \\
\text { branches now have the same ledger system. }\end{array}$ \\
\hline $\begin{array}{l}\text { Filing } \\
\text { rooms }\end{array}$ & \multicolumn{2}{|c|}{$\begin{array}{l}\text { Exist as the 'ultimate accounting spaces' and the private spaces of the accounting } \\
\text { clerks in the branches, Head Office and the manufacturing sites. Most seem messy } \\
\text { to an outsider but 'in order' to the account clerks holding the key to them. }\end{array}$} \\
\hline SAP & & $\begin{array}{l}\text { Replaced ConsolEx and S\&D Excel. Only } \\
\text { two modules in use: accounting and partial } \\
\text { HRM. Operates as the mediating instru- } \\
\text { ment between the centre and the periphery. } \\
\text { Made the accounting actor-network efficient } \\
\text { in terms of ability to produce financial } \\
\text { information, but this still has no significant } \\
\text { impact, either upon day-to-day operational } \\
\text { controls and planning or on strategic deci- } \\
\text { sion making. Redefined and empowered the } \\
\text { political role of the FD and created a new } \\
\text { political alliance of accounting' between } \\
\text { the centre and the periphery. Identity of ac- } \\
\text { counting clerks was redefined as belonging } \\
\text { to the centre rather than the periphery even } \\
\text { though they are physically located in the } \\
\text { periphery. }\end{array}$ \\
\hline
\end{tabular}

\section{Accounting} decoupled

How and

Alawattage

2012

A working paper.

Please do not quote without authors' prior

approval
Ledger ac-
counts

Continue to exist in manual form as the Crimary means of day-to-day recording of 
Figure 1: Processual transformation of accounting regime

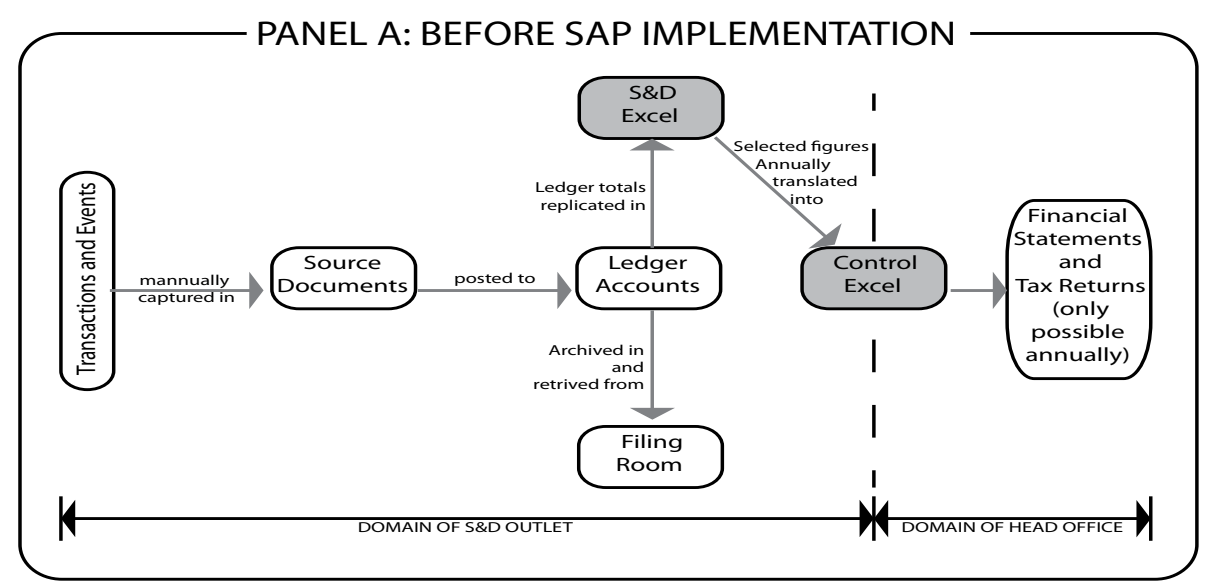

\section{Accounting} decoupled

How and

Alawattage

2012

A working paper. Please do not quote without authors' prior approval

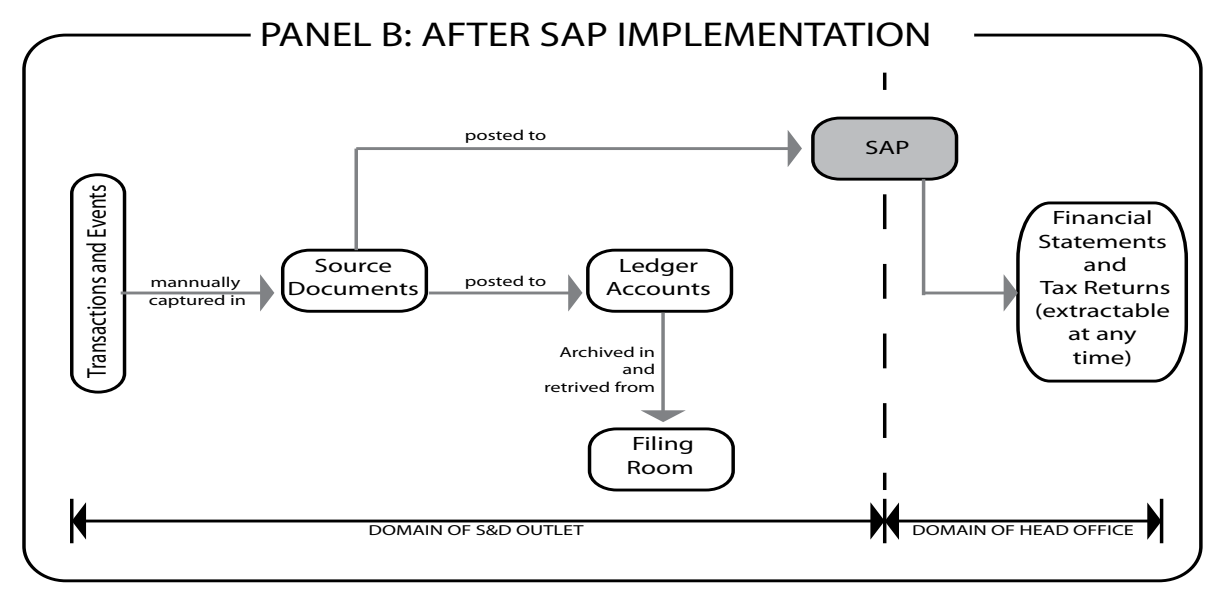

\section{Discussion and conclusions}

The accounting regime is conceptualised here as a particular configuration of and connection between actor-worlds of accounting actants; human and nonhuman, both exercising an equal power over each other to define and redefine their identities as accounting actants. In our case, such accounting actants were FD, accounting clerks, ledger books and accounts, Excel-based accounting templates (ControlEx and S\&D Excel), filing rooms, SAP and external SAP consultants. They all became 'accounting actants' by their own definition as well as by others' definition of them as 'accounting. Also, they became 'accounting' by their and others' definition of others as 'non-accounting. Hence, although they had officially been engaged in the SAP implementation process, manufacturing site managers and S\&D outlet managers would never be identified as someone belonging to this accounting network, either by those in the network or by themselves, but as invited guests and 'trans-actants' of the accounting network. It is this inclusion of and exclusion from the network that provides a site-specific definition of an accounting. By inclusion in the accounting net- 
work, objects become 'accounting. For example, in LC the filing room was always defined as an 'accounting space', which non-accounting personnel would not enter unless accompanied by accounting personnel. Similarly, despite its high IT content and the involvement of non-accounting personnel in the design and implementation process, SAP has also been introduced and defined as an accounting object owned by the accounting actor-network. As such, the accounting regime is "realised through the common 'enrolling' of human and non-human participants into a network through processes of 'negotiation' and 'translation"' (Hassard et al. , 1999, p.388).

Power is accomplished mainly through enrolling such attributes in the actornetwork to (re)distribute, attach and detach 'mediating instruments' (see Miller and O'Leary, 2007, and also Munro, 1999, p.430) or 'boundary objects' (see Briers and Chua, 2001) across actor-networks. In LC, ledger accounts, financial reports, Excel templates, memos, circulars and accounting instruction sheets have always been mediating instruments through which actors in the periphery were associated with the administrative centre. However, in the pre-SAP accounting regime that association between the periphery and the centre was ritualistic and periodic: mediating instruments (e.g. ControlEx) were issued periodically to integrate the accounting actor-network which otherwise was coupled only loosely with the administrative centre. The accounting network had no instrumental powers to associate the periphery with the centre on a day-to-day basis. ANT emphasises the shifting composition of the hybridity between human and non-human actants, and as such, "any redistribution of materials facilitates shifts in arrangements between humans and technology and therefore creates possibilities for new associations" of power (Munro, 1999, p.430). SAP, replacing the familiar ControlEx and S\&D Excel, empowered the accounting network by facilitating a new association of power with the accounting function in the periphery. This marked a regime change in the accounting network because there was a shift in the power of the accounting network to connect the periphery with the centre. As the translator-spokesperson of the accounting actor-network, the FD also became the point at which these newly gained powers of the accounting actor-network manifested. Accounting reports that he can extract from his 'actor-networked' computer terminal, his formal and informal knowledge of what goes on in the periphery, his political alliances with the peripheral accounting personnel, facilities that he (and "[his] people") claims to provide to the non-accounting trans-actants and also the "sound relationships" that he and "[his] people" claim to maintain with them are all manifestation of the power of this reformed accounting actor-network. Though often manifested through the actions and outcomes associated with key actors, power is governed through the actor-network: accounting instruments collectively become an accounting regime by enrolling themselves in an actor-network which, in turn, receives its accounting identity through that enrolment of actants as 'accounting', not otherwise.

This means that there was certain accounting which never registered as accounting' in the accounting actor-network. Product costing and pricing were evidently such an accounting activity which never got enrolled with the ac- 
counting actor network. Both before and after SAP, there has neither been a separate management/cost accounting function nor such accounting been assumed by the accounting people. Instead product costing and pricing have always been the "experienced and intuitive" job of the manufacturing plants and S\&D managers. They never deployed any sophisticated calculative practices to determine these. Cost calculations have never been anything more than a rough estimation of the prime cost, which is the basis that FD used for inventory valuations after annual stock takings at manufacturing sites and S\&D outlets. While this prime cost seemed to be vaguely operating as a lower bench mark, pricing has often been a 'political and patronised act', especially in the case of "tendering" to government supply contracts. Capacity to perform such "political and patronised acts" of pricing and sales has always been the embodied social capital of S\&D people. As an S\&D manager once commented, "In this business, you offer a price not for what you sell but to the person with whom

Accounting decoupled

How and

Alawattage

2012

A working paper. Please do not quote without authors' prior approval you do business for a long time".

While ideals of integration, standardisation and networking have been achieved within the accounting function to a certain extent through SAP, accounting has always been decoupled from the operations. So, why does accounting never gain (both before and after SAP implementation) the ability to offer the nonaccounting actor-worlds a set of operational doctrines to govern their interactions and practices? First, in this particular case, the answer lies in the way in which the accounting actor-network itself is constructed and enabled. As we mentioned above, the accounting actor-network is defined and redefined by the enrolment and association of certain actors as 'accounting' and disassociation of others as 'non-accounting. This particular enrolment has a paradoxical impact. On the one hand, it enables and empowers the accounting actor-network to perform its own introvert functions more effectively. As far as our case company is concerned, the primary set of activities and responsibilities that the accounting actor-network has registered itself with has been the recording transactions with the aim of producing financial statements, the purpose of which has mainly been to meet the legal accountabilities of the firm apart from regular facilitation of non-accounting actors to check the dues and owes of the people they are dealing with and the availability of cash to handle them. Such information provided by accounting actor network did not impose any checks and controls on the operations such as credit controls. On the other hand, paradoxically, it hinders the potential of these objects to penetrate into non-accounting actor-worlds. This is quite contrary to the Western experience that SAP is often defined and enrolled as a 'non-accounting actant' and associated with 'non-accounting' actor-worlds (such as engineering, production and logistics) where the role of accounting personnel, especially management accountants, is redefined and enrolled into the actor-networks of business-process management (see Caglio, 2003, Dechow and Mouritsen, 2005, Dillard and Yuthas, 2006, Scapens and Jazayeri, 2003). The integrative function of SAP and the diffusion of accounting into the domains of line management are hardly evident. The SAP implementation in our case has lessened the vertical decoupling to a large extent but not the horizontal decoupling between accounting and operations. 
Second, the parameters of accounting arise not only from the politics of the particular network in question but also from the isomorphic adoption (see DiMaggio and Powell, 1983) of 'global' accounting objects: objects through which "rationalised myths" (see Meyer and Rowan, 1977) are institutionalised to frame performativity of accounting. They determine the official parameters within which transactions are understood, captured, recorded, analysed and reported. As such an object and as a non-human actant, SAP (as well as traditional accounting templates and procedures) inherits certain obstinate qualities of the bureaucratic apparatus of Western modernity: for ideal performance, it demands that the business be defined as a set of bureaucratic, arms-length, and impersonal interactions and transactions between parties acting upon a set of legal, economic and bureaucratic rationales (see Meyer and Rowan, 1977, p.342), which in turn are brought in to model the business processes as 'best practice'-a set of structures, processes, policies and protocols that "reflect the myths of their institutional environments instead of the demands of their work activities" (Meyer and Rowan, 1977, p.341). This also implies, at a structural level, a clear separation between the polity, society and the economy so that the economic rationales of private capital can be relatively independent of the patronage relations of the civil and political states (see Weber, 1961). Our case studies a company far from this modernity and its bureaucratic rationales. Its market context is heavily 'imperfect', defined by political patronage and personal connections which operational managers often identify as one of the most valuable assets they have. The recent success of the company is attributed by and large to its penetration into the local political state through building "political connections without which this sort of company cannot succeed, because our biggest customer is still the local government" (S\&D manager). Even though the importance of such political connections is well discussed and acknowledged in the public and business media, they always remain a 'shadow system, ${ }^{5}$ the establishment of, and ability to capitalise on, which involve operational costs and investments that cannot be narrated within the organisational apparatus of modernity. Accounting, being such an 'official' apparatus, finds it difficult to represent this 'shadow system' and to offer an operational doctrine to govern the real business processes that naturally run within this shadow. In other words, real business processes are often too political to be narrated within the apparatuses of accounting that manage the 'official' interface of the company matters.

For smooth functioning, this shadow system demands a certain degree of operational independence, distance and secrecy from the organisational formalities. So, decoupling it from the politically capitalised and patronised operational core, accounting is attributed an important role of managing the communicative interface between the company and the state camouflaging the imperfections' with which business operates. So, accounting classification of expenses often become the hiding grounds for various political payments. Accounting

5 Even though we call these political patronage and connections a 'shadow system', they are the primary grounds upon which the business operations are founded and run. We label them 'shadow' because they always remain something that would not be acknowledged within 'formal' (or rather "mythical") organisational protocols. 
is important and performs the function of legitimating the existence of the company as a 'modern' institution. As such, accounting becomes the medium through which a modernity is imputed to the corporate entity to legitimise its existence as a limited liability company; a corporate personality that becomes vital within interactions with the formal protocols of the political state. SAP never redefined this external communicative role of accounting, but just reinforced and enhanced it. Accounting categories simply provided an 'official' space within which 'political imperfections' of the business could be camouflaged. In other words, due to the ostensive characteristics of accounting (with or without SAP) that frame performativity of the accounting actor network, the accounting actor-network never had a chance to infiltrate the non-accounting actor-worlds as an operational doctrine. Instead, it has always been confined to a fairly important role: 'shadowing' the political and patronage processes behind business's 'official' interface. As such, FD's functional expectation of panoptic visibility of branch activities through SAP runs contradiction to an operational necessity of decoupling and camouflaging from 'official' communication that any kind of accounting would do. Decoupling has always been an operational necessity imposed by the 'political imperfections' of the way the Malaysian businesses (like many other LDCs) are supposed to operate and panoptic dreams associated with SAP and other modern computer accounting packages can hardly be realised within such non-modern conditions.

\section{References}

Alawattage C, Wickramasinghe D. 'Appearance of accounting in a political hegemony.' Critical Perspectives on Accounting. 2008;19:293-339.

Alawattage C, Wickramasinghe D. 'Institutionalisation of control and accounting for bonded labour in colonial plantations: A historical analysis.' Critical Perspectives on Accounting. 2009;20:701-15.

Berry AJ, Capps T, Cooper D, Ferguson P, Hopper T, Lowe EA. Management control in an area of the NCB: Rationales of accounting practices in a public enterprise. Accounting, Organizations and Society. 1985;10:3-28.

Bourdieu P. 'The Forms of Capital'. In: Richardson JG, editor. Handbook of Theory and Research for the Sociology of Education. New York: Greenwood Press; 1986. pp. 241-58.

Briers M, Chua WF. 'The role of actor-networks and boundary objects in management accounting change: a field study of an implementation of activity-based costing.' Accounting, Organizations and Society. 2001;26:237-69.

Caglio A. 'Enterprise Resource Planning systems and accountants: towards hybridization?' European Accounting Review. 2003;12:123-53.

Callon M. 'The sociology of an actor-network: the case of the electrical vehicle.' In: Callon M, Law J, Rip A, editors. Mapping the dynamics of science and technology: sociology of sciences in the real world. London: Macmillan Press; 1986a. pp. 19-34. 
Callon M. 'Some elements of sociology of translation: domestification of the scallops and the fishermen of St Brieuc Bay.' In: Law J, editor. Power, action and belief: a new sociology of knowledge? London: Routledge \& Kegan Paul; 1986b. pp. 196-233.

Chapman C, Chua WF. 'Technology-driven integration, automation, and standardisation of business processes.' In: Bhimani A, editor. Management accounting in the digital economy. Oxford: Oxford University Press; 2003. pp. 74-94.

Chapman CS. 'Not because they are new: Developing the contribution of enterprise resource planning systems to management control research.' Accounting, Organizations and Society. 2005;30:685-9.

Covaleski MA, Dirsmith MW. 'Budgeting as a means for control and loose coupling.' Accounting, Organizations and Society. 1983;8:323-40.

\section{Accounting} decoupled

How and

Alawattage

2012

A working paper. Please do not quote without authors' prior approval

Davenport TH. 'Putting the Enterprise into the Enterprise System.' Harvard Business Review. 1998;July-August:121-31.

Davenport TH. Mission critical: realizing the promise of enterprise systems. Boston, Mass.: Harvard Business School Press; 2000.

Dechow N, Mouritsen J. 'Enterprise resource planning systems, management control and the quest for integration.' Accounting, Organizations and Society. 2005;30:691-733.

Dillard JF, Yuthas K. 'Enterprise resource planning systems and communicative action.' Critical Perspectives on Accounting. 2006;17:202-23.

DiMaggio PJ, Powell WW. 'The Iron Cage Revisited: Institutional Isomorphism and Collective Rationality in Organizational Fields'. American Sociological Review. 1983;48:147-60.

Emmanuel C, Otley D, Merchant K. Accounting for management control. 2nd ed. London: Chapman \& Hall;1990.

Hassard J, Law J, Lee N. 'Preface.' Organization. 1999;6:387-90.

Hoque Z, Hopper T. 'Rationality, accounting and politics: a case study of management control in a Bangladeshi jute mill'. Management Accounting Research. 1994;5:5-30.

Hyvönen T, Järvinen J, Pellinen J. 'The role of standard software packages in mediating management accounting knowledge.' Qualitative Research in Accounting \& Management. 2006;3.

Hyvönen T, Järvinen J, Pellinen J. 'A virtual integration-The management control system in a multinational enterprise.' Management Accounting Research. 2008;19:45-61.

Jack L, Kholeif A. 'Enterprise Resource Planning and a contest to limit the role of management accountants: A strong structuration perspective.' Accounting Forum. 2008;32:30-45.

Kholeif AOR, Abdel-Kader M, Sherer M. 'ERP customization failure: Institutionalized accounting practices, power relations and market forces.' Journal of Accounting \& Organizational Change. 2007;3.

Mackintosh, N. B. Management accounting and control systems: an organizational and behavioral approach. London: John Wiley \& Sons; 1994. 
McAdam R, Galloway A. 'Enterprise resource planning and organisational innovation: a management perspective.' Industrial Management \& Data Systems. 2005;105:280-90.

Meyer J. W., Rown B. 'Institutionalised organizations: formal strcuture as myth and ceremony’' American Journal of Sociology. 1977; 83:340-363.

Miller P, O’Leary T. 'Mediating instruments and making markets: Capital budgeting, science and the economy' Accounting, Organizations and Society. 2007;32:701-34.

Munro R. 'Power and Discretion: Membership Work in the Time of Technology.' Organization. 1999;6:429-50.

Quattrone P. 'Commenting on a commentary?: Making methodological choices in accounting.' Critical Perspectives on Accounting. 2004;15:232-47.

Quattrone P, Hopper T. 'What does organizational change mean? Speculations on a taken for granted category'. Management Accounting Research. 2001;12:403-35.

\section{Accounting}

decoupled

How and

Alawattage

2012

A working paper. Please do not quote without authors' prior approval

Quattrone P, Hopper T. 'A "time-space odyssey": management control systems in two multinational organisations.' Accounting, Organizations and Society. 2005;30:735-64.

Quattrone P, Hopper T. 'What is IT? SAP, accounting, and visibility in a multinational organisation.' Information and Organization. 2006;16:212-50.

Scapens RW, Jazayeri M. 'ERP systems and management accounting change: opportunities or impacts? A research note.' European Accounting Review. 2003; $12: 201-33$.

Uddin S, Hopper T. 'A Bangladesh soap opera: privatisation, accounting, and regimes of control in a less developed country.' Accounting,Organizations and Society. 2001;26:643-72.

Weber M. General economic history. New York: Collier Books; 1961.

Weick KE. 'Educational organizations as loosely coupled systems.' Administrative Science Quarterly. 1976;21:1-19.

Wickramasinghe D, Hopper T. 'A cultural political economy of management accounting controls: a case study of a textile Mill in a traditional Sinhalese village.' Critical Perspectives on Accounting. 2005;16:473-503. 


\section{Appendix 1: Fieldwork details}

\begin{tabular}{|c|c|}
\hline $\begin{array}{l}\text { Phase of the field } \\
\text { work }\end{array}$ & Activities undertaken \\
\hline $\begin{array}{l}\text { First visit } \\
\text { Dec } 2006 \text { - Jan } \\
2007 \\
\text { 4-week duration }\end{array}$ & $\begin{array}{l}\text { First author was introduced by the FD to the senior managers and accounts } \\
\text { clerks at head office as his close friend and a researcher interested in 'learn- } \\
\text { ing' how accounting was done in the company and how accounting can be } \\
\text { improved through SAP. } \\
\text { Tried to develop a network of connections with them through lunch breaks } \\
\text { and 'yam cha' (tea sessions late at night) to grasp a sense of the corporate } \\
\text { culture through the clerks. } \\
\text { Conversed with the accounts clerks, observed their work routines, docu- } \\
\text { mented their filing systems, paper trails, and the manual accounting system at } \\
\text { head office. } \\
\text { Visited and spent a week in one of the S\&D outlets in JB. } \\
\text { Conducted semi-structured interview with the S\&D manager to understand } \\
\text { how the accounting system works at the branch/outlet level. The interview } \\
\text { lasted for about } 40 \text { minutes. } \\
\text { Freely conversed with S\&D accounts clerks about their work routines, ob- } \\
\text { served and documented their daily activities, filing system used, paper trails, } \\
\text { and their accounting flow. }\end{array}$ \\
\hline $\begin{array}{l}\text { Second visit } \\
\text { July } 2007 \text { - Sept } \\
2007 \\
11 \text { week duration }\end{array}$ & $\begin{array}{l}\text { Revisited head office to catch up with the FD and the accounts clerks } \\
\text { Conducted four formal semi-structured interviews with FD, with each lasted } \\
\text { about } 35 \text { to } 40 \text { minutes. } \\
\text { Issues discussed include the testing phase and the actual roll out of SAP, prob- } \\
\text { lems they faced both technically and human issues such as training, resistance } \\
\text { etc, change in work routines etc. } \\
\text { In addition, numerous unofficial personal catch-up with the FD during 'yam } \\
\text { cha' sessions to understand more about the roll out process at head office and } \\
\text { other S\&D outlets, training programmes in place, changes to the accounting } \\
\text { system and routines, changes in personnel arrangements. } \\
\text { Carried out observations at the head office, documented the daily accounting } \\
\text { routines of accounts clerks after SAP. } \\
\text { Conversed with the accounts clerks during lunch breaks and late night 'yam } \\
\text { cha' to obtain a sense of their 'true' feelings with the use of SAP and whether } \\
\text { or not this has improved / affected their work (good and bad). } \\
\text { Visited S\&D outlets in JB and Selangor (those outlets were the first few to } \\
\text { receive SAP roll out) and carried out interviews with each S\&D manager. } \\
\text { Conversed with the accounts clerks at all four S\&D outlets outside their work- } \\
\text { ing environment (i.e. lunch breaks and late night tea sessions preferred) } \\
\text { Issues discussed include their opinions on SAP implementation at their offices, } \\
\text { how this changed their work routines, training sessions they have attended } \\
\text { and how those helped with their daily operation activities etc. } \\
\text { Observed the daily operational routines at the outlets, observed and docu- } \\
\text { mented the accounting process after SAP, attended the SAP training sessions } \\
\text { organised for the accounts clerks. }\end{array}$ \\
\hline
\end{tabular}

\section{Accounting decoupled}

How and

Alawattage

2012

A working paper.

Please do not quote without authors' prior approval
Third visit

Dec 2007

4-week duration
Stationed at the two S\&D outlets in Pulau Pinang as these outlets have just started the roll out process.

Managed to interview the outlet managers, two interviews each, ranging between 30 and 40 minutes during each interview.

Observed the roll out process especially the reactions of the accounts clerks and the outlet managers when they carried out their daily accounting activities.

Observed and documented the accounting processes at these outlets, examined the accounting and SAP documents.

Attended the SAP training sessions to get a sense of how these sessions were conducted and to observe the reactions of the accounts clerks while they were learning to use SAP.

Conversed with the accounts clerks outside their normal work settings. Issues discussed were similar to those discussed at the head office and other S\&D outlets, in addition to other matters which the Pulau Pinang S\&D accounts clerks deemed important. 


\section{Fourth visit July 2007 - Aug} 2008

8 -week duration
Revisited head office and the two S\&D outlets in JB for two weeks to observe the daily accounting practices and work routines after nearly one year of SAP implementation.

Carried out informal 'chats' with the FD and the accounts clerks at the head office to follow up with their perceptions in terms of how SAP has changed their routines and working environment, their opinions as to the success / failure of SAP, effectiveness of SAP etc.

Observed and documented the day-to-day operations and accounting activities of the accounts clerks, filing systems used after the SAP was put in place. Carried out similar activities at the JB S\&D outlets to observe the differences one year after SAP implementation.

Also visited S\&D outlets in Selangor and Pulau Pinang, spent about 1 week in each location.

Observed and documented the progression in SAP implementation at these outlets, carried out informal conversations with the managers and the accounts clerks to grasp a sense of their perceptions and 'feelings' towards the use of SAP, how SAP changed their working routines, their 'authority', effectiveness of SAP etc.

Roll out processes were in progress at S\&D outlets in Kelantan and Pahang, hence the first author spent 2 weeks in each location to follow their progress. Observations, documentations, and conversations were carried out with the outlet managers and accounts clerks at both locations to understand the preparations, training, and changes made while getting ready for SAP implementation.

Training sessions were attended and documented; SAP meetings were also attended and documented.
Fifth and final visit Dec 2008 1-month period

The first author first revisited the S\&D outlets in Kelantan and Pahang to observe and document the changes in place after her last visit back in August 2008.

Semi-structured interviews were conducted with the managers and informal meetings and conversations were carried out with the accounts clerks at both locations to understand the progress after 6 months of SAP implementation. Issues involving the changes in areas such as work routines, accounting practices, filing system, authorities and personnel were explored and discussed. As before, observations and documentations were carried out while the first author was at the outlets

The first author then spent the remaining two weeks travelling between Selangor and JB to revisit the outlets at both locations and also the head office. In each location, informal conversations were carried out with the accounts clerks and the main issues were documented.

Observations and documentations were carried out on site to understand further the changes on work routines, personnel, authority, and accounting routines after the last visit.

Due to time constraint, the first author was not able to visit the outlets in $\mathrm{Pu}$ lau Pinang. However, the first author was able to follow up with the manager and the accounts clerks via telephone conversations to obtain updates on the current accounting environment and routines.

Periods when the first author was stationed in the UK
A series of networks of connections were built up by the first author with the accounts clerks and the managers during her each visit to the different locations. Based on such networks, she can then carried out series of Skype calls with these main actors while away from the research sites and still be able to obtain updates with regards to the progress of SAP implementation.

Follow-ups and clarifications can also be obtained through emails and Skype calls while writing up the research case.

\section{Accounting decoupled} How and Alawattage 2012

A working paper. Please do not quote without authors' prior approval 


\section{Appendix 2: Geography of the corporate actor-network}

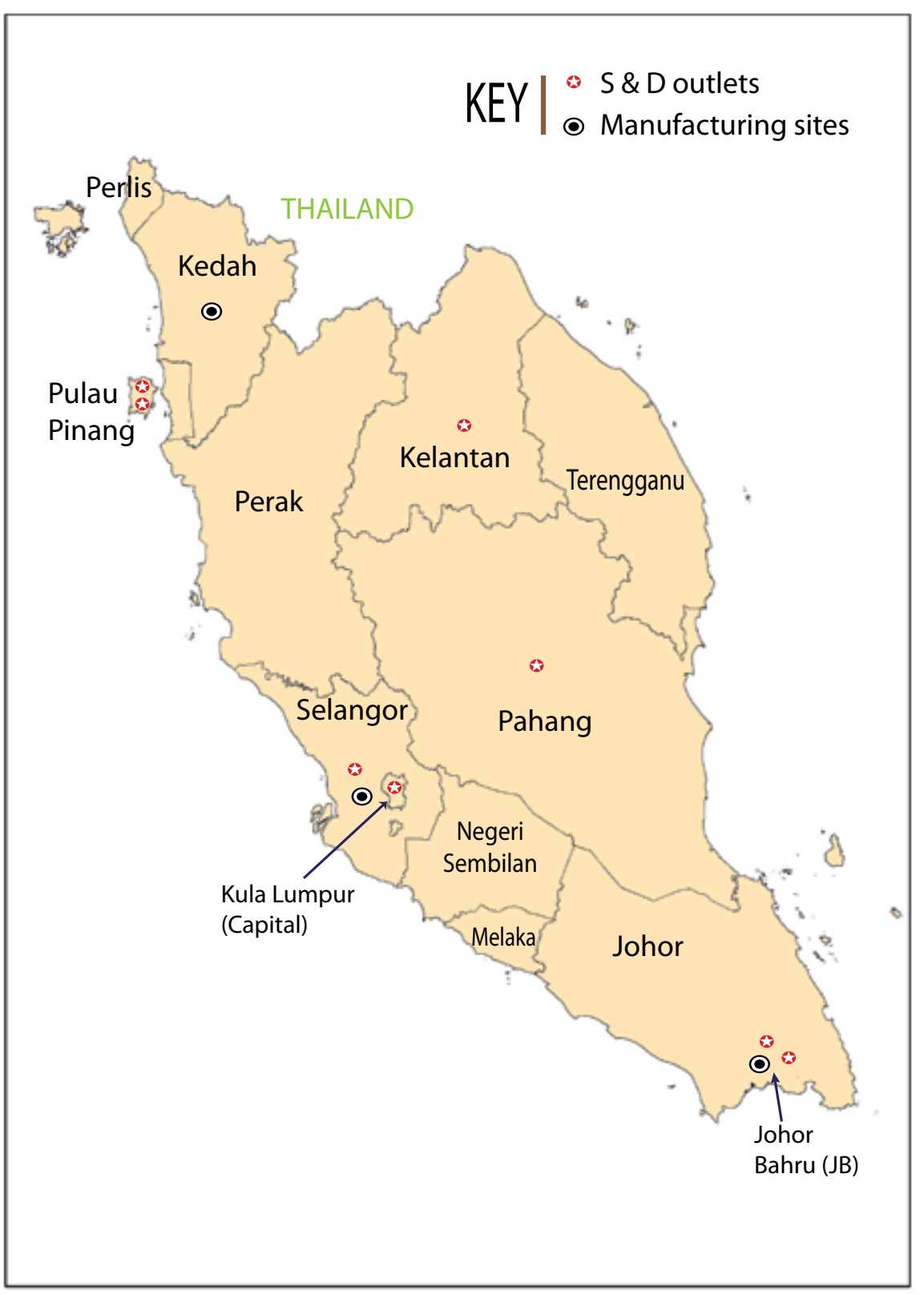

\section{Accounting}

decoupled How and Alawattage 2012

A working paper. Please do not quote without authors' prior approval 